\title{
A comparative study of transcervical foley's catheter with intracervical PGE2 gel for pre-induction cervical ripening
}

\author{
Anupma $^{1 *}$, U. Karya ${ }^{2}$, Harsha S. Gaikwad ${ }^{1}$, Anamika $^{1}$, Shalini ${ }^{1}$
}

\begin{abstract}
${ }^{1}$ Department of Obstetrics and Gynecology, V. M. M. C. and Safdarjung Hospital, New Delhi, India ${ }^{2}$ Department of Obstetrics and Gynecology, Lala Lajpat Rai Memorial Medical College and S. V. B. P. Hospital Meerut, Uttar Pradesh, India
\end{abstract}

Received: 25 March 2020

Accepted: 22 April 2020

*Correspondence:

Dr. Anupma,

E-mail: ms.anupma245@gmail.com

Copyright: () the author(s), publisher and licensee Medip Academy. This is an open-access article distributed under the terms of the Creative Commons Attribution Non-Commercial License, which permits unrestricted non-commercial use, distribution, and reproduction in any medium, provided the original work is properly cited.

\begin{abstract}
Background: To compare the efficacy of transcervical foley's catheter with intracervical PGE2 gel for pre -induction cervical ripening.

Methods: It was a prospective interventional study conducted between April 2012 to April 2013 in the department of obstetrics and gynecology at L. L. R. M. medical college and S. V. B. P. hospital Meerut. A total of 80 pregnant women of $\geq 28$ weeks of gestation with bishop score less than or equal to 4 and with various indications for induction of labour were randomly allocated to receive intracervical PGE2 gel (Group A) or transcervical foley's catheter (Group B). Bishop score was repeated after 6 hours by the same person and the results were compared.

Results: The groups were comparable with respect to maternal age, gestational age, indications of induction of labour and initial bishop's score. The intragroup results were calculated by Wilcoxon signed rank test and intergroup results were calculated by Mann Whitney U-test. The change in bishop score in PGE2 group was 3 and in foley's group was 3.25 after 6 hours of induction (interquartile range of median) which is significant. The mean change in bishops score was 2.65 in PGE2 group and 3.1 in foley's group after 6 hours of induction and was significant, however the bishop's score was comparable in both the groups and statistically insignificant.

Conclusions: Both foley's catheter and PGE2 gel are equally effective in pre-induction cervical ripening of cervix.
\end{abstract}

Keywords: Foley's catheter, PGE2 gel, Pre-induction cervical ripening of cervix

\section{INTRODUCTION}

Induction of labour is a common obstetric practice according to most current studies, the rate being $9.6 \%$ worldwide (WHO global survey). ${ }^{1}$ In the absence of ripe or unfavourable cervix successful vaginal delivery is less likely therefore the cervical ripening or preparedness for induction should be assessed before the regime is selected. In case the bishop's score is $\leq 4$, a cervical ripening agent must be used before the induction of labour Moreover as a general principle induction of labour is undertaken when continuation of pregnancy is associated with greater level of maternal and fetal risk. ${ }^{2}$
Although a variety of specific clinical circumstances may indicate the need for induction of labour, the essential judgement that a clinician must make is whether the interests of the mother or the baby or both will be better served by ending or continuing the pregnancy, but while making the judgement it is necessary to understand the actual risk of continuing the pregnancy as well as possible consequences of the method employed in response to induction of labour.

Cervical ripening usually begins before the onset of labour, Contractions are necessary for cervical dilatation. This study is designed with a view to assess and compare 
the efficacies of intracervical PGE2 gel and transcervical foley's catheter for cervical ripening, need for augmentation of labour, induction delivery interval and maternal and fetal outcomes.

\section{METHODS}

This study was conducted at Lala Lajpat Rai Memorial medical college and associated S. V. B. P. Hospital, Meerut from April 2012 to April 2013 after ethical committee approval. The study population $(n=80)$ consisted 80 pregnant women with gestational age $\geq 28$ weeks of gestation with various indications of induction of labour. An informed and written consent was taken from the participants.

\section{Inclusion criteria}

- Singleton pregnancy

- Cephalic presentation

- $\quad$ Bishop's score $\leq 4$

- Intact membranes

- Post-dated pregnancy

- Hypertensive disorders of pregnancy

- Diabetes

- Fetal growth restriction

- Recent intrauterine death

- Fetal congenital malformations.

\section{Exclusion criteria}

- Multiple pregnancy

- Malpresentation

- Absent membranes

- Antepartum haemorrhage

- Pelvic structural abnormality

- Active genital herpes infection

- Bronchial asthma.

The patients were randomly allocated to either PGE2 gel group (Group $\mathrm{A} ; \mathrm{n}=40$ ) and foley's group (Group B; $\mathrm{n}=40$ ). Each patient thoroughly examined and pre- induction bishop's scoring done at the time of admission. Post-induction bishop's scoring was done after 6 hours, preferably by the same person. Improvement in bishop's score, induction delivery interval, mode of delivery, fetal and maternal outcome were noted. Dose repetition of PGE2 was done every 6 hours until there is onset of labour or bishop's score becomes $>6$ (maximum 3 doses). Need for augmentation of labour was assessed and implemented by other methods such as artificial rupture of membranes, oxytocin drip or both.

Foley's catheter induction was done using the catheter of 16 fringe size. Under all aseptic precautions the catheter introduced though the cervical os and the bulb inflated with $30 \mathrm{cc}$ saline and the catheter was taped to patient's thigh to maintain traction. After 6 hours bishop scoring done and catheter was also checked for extrusion of balloon from cervix and adjusted to continue gentle traction if not extruded. Fetal heart rate was assessed from time to time.

When catheter expelled spontaneously and cervix found to be favourable or uterine contractions established, ARM was done or ARM+ oxytocin or oxytocin drip started, and patient watched for further progression of labour. Failure of induction was considered if patient failed to go into labour even after 24 hours of introduction of inducing agent.

\section{Statistical analysis}

The $\mathrm{p}$ value of $<0.005$ was considered statistically significant.

\section{RESULTS}

PGE2 group and foley's group had 40 randomised women each. Both groups were comparable with respect to maternal age, gestational age, indication for induction of labour and pre-induction bishop's score (Table 1, 2, 3). The mean gestational age in both groups were comparable and the difference was statistically insignificant ( $\mathrm{p}$-value $>0.005$ ).

Table 1: Distribution of patients according to age.

\begin{tabular}{|lllll|}
\hline Maternal age (in years) & Group A ( $\mathbf{n = 4 0 )}$ & Group B (n=40) & p-value & Significance \\
\hline $21-25$ & 25 & 21 & \\
\hline $26-30$ & 14 & 15 & \\
\hline$>30$ & 1 & 4 & & \\
\hline Mean \pm SD & $25.5 \pm 1.91$ & $25.58 \pm 2.85$ & 0.006 & Not significant \\
\hline
\end{tabular}

In this study the change in bishop's score after 6 hours in PGE2 group was 3 and in foley's group was 3.25 (interquartile range of median). The mean change in bishop score in PGE2 gel group was 2.65 and in foley's group was 3.1 which was significant, however the comparison between the two groups revealed that one 
Table 2: Distribution of patients according to gestational age.

\begin{tabular}{|lllll|}
\hline Gestational age (in weeks) & Group A $(\mathbf{n}=\mathbf{4 0})$ & Group B $(\mathbf{n}=\mathbf{4 0})$ & p-value & Significance \\
\hline $28-30$ & 0 & 3 & & \\
\hline $31-35$ & 3 & 12 & & \\
\hline $36-40$ & 19 & 20 & & \\
\hline$>40$ & 18 & 15 & & \\
\hline Mean \pm SD & $39.05 \pm 2.966$ & $39.05 \pm 2.187$ & 0.644 & Not significant \\
\hline
\end{tabular}

Table 3: Distribution of patients according to pre-induction Bishop's score.

\begin{tabular}{|lllll|}
\hline Initial Bishop's score & Group A $(\mathbf{n}=\mathbf{4 0})$ & Group B (n=40) & p-value & Significance \\
\hline 0 & 5 & 4 & & \\
\hline 1 & 9 & 7 & & \\
\hline 2 & 15 & 13 & & \\
\hline 3 & 9 & 12 & & \\
\hline 4 & 2 & 4 & 0.332 & Not significant \\
\hline Mean bishop's score & 1.85 & 2.125 & 0.18 & Not significant \\
\hline Median bishop's score ( $\left.\mathrm{q}_{1}\right)$ in $75 \%$ of cases & 3 & 2.75 & & \\
\hline
\end{tabular}

Table 4: Distribution of patients according to the changes in Bishop score after 6 hours.

\begin{tabular}{|lllll|}
\hline Bishop score & Group A $(\mathbf{n}=\mathbf{4 0})$ & Group B (n=40) & p-value & Significance \\
\hline $90 \mathrm{R}>9$ & 2 & 1 & & \\
\hline 8 & 2 & 3 & & \\
\hline 7 & 2 & 4 & & \\
\hline 6 & 5 & 8 & & \\
\hline 5 & 7 & 10 & & \\
\hline 4 & 11 & 8 & & \\
\hline 3 & 10 & 5 & & \\
\hline 2 & 0 & 1 & & \\
\hline Mean Bishop score & 4.5 & 5.2 & & \\
\hline Mean change in Bishop's score & 2.65 & 3.1 & & \\
\hline Median Bishop score $\left(\mathrm{q}_{3}\right)$ & 6 & 6 & 0.00 & Significant \\
\hline Median change in Bishop score $\left(\mathrm{q}_{3}-\mathrm{q}_{1}\right)$ & 3 & 3.25 & \\
\hline
\end{tabular}

*Intra group calculated by Wilcoxon signed rank test, *Inter group calculated by Mann Whitney U test.

Table 5: Distribution of patients according to duration of induction to onset of labour (in hours).

\begin{tabular}{|lllll|}
\hline Duration of induction and onset of labor & Group A $(\mathbf{n}=\mathbf{4 0})$ & Group $\mathbf{B}(\mathbf{n}=\mathbf{4 0})$ & p-value & Significance \\
\hline $3-6$ & 3 & 3 & & \\
\hline $6-9$ & 13 & 13 & \\
\hline $9-12$ & 11 & 11 & \\
\hline $12-15$ & 7 & 6 & & \\
\hline $15-24$ & 6 & 7 & & \\
\hline$>24$ hours & 0 & 0 & & \\
\hline Mean & $11.008 \pm 4.3$ & $10.94 \pm 3.1$ & 0.718 & Not significant \\
\hline
\end{tabular}

The mean change in Bishop's score was significant in both the groups after 6 hours of induction. The Bishop's score after 6 hours was comparable in both groups and statistically insignificant. In this study the mean duration of induction to onset of labour were also compared. The mean duration of onset of labour in PGE2 group was $11.008 \pm 4.3$ hours and foley's group was $10.94 \pm 3.1$ hour and p-value 0.718 . The difference between these two 
groups was comparable and statistically insignificant (pvalue $>0.005$ ) (Table 5). In none of the patients the duration of induction to onset of labour was found $>24$ hours. The need for further augmentation of labour and induction delivery interval was also studied and compared in both the groups.

Table 6: Distribution of patients according to induction and delivery interval.

\begin{tabular}{|lllll|}
\hline Induction delivery interval (in hours) & Group A $(\mathbf{n = 4 0 )}$ & Group B $(\mathbf{n = 4 0})$ & p-value & Significance \\
\hline $4-8$ & 0 & 11 & \\
\hline $8-12$ & 4 & 13 & \\
\hline $12-16$ & 5 & 9 & \\
\hline $16-20$ & 21 & 3 & \\
\hline $20-24$ & 8 & 1 & \\
\hline$>24$ & 2 & $18.22 \pm 4.1$ & 0.791 & Not significant \\
\hline Mean & $18.12 \pm 3.68$ & & & \\
\hline
\end{tabular}

Table 7: Distribution of patients according to the need for augmentation.

\begin{tabular}{|lllll|}
\hline Type of augmentation & Group A $(\mathbf{n}=\mathbf{4 0})$ & Group B $(\mathbf{n = 4 0})$ & p-value & Significance \\
\hline Spontaneous delivery & $20(50 \%)$ & $17(42.5 \%)$ & $>0.05$ & Not significant \\
\hline Arm & $7(17.5 \%)$ & $5(12.5 \%)$ & $>0.05$ & Not significant \\
\hline Oxytocin & $9(22.5 \%)$ & $15(37.5 \%)$ & $>0.05$ & Not significant \\
\hline Arm+ oxytocin & $4(10 \%)$ & $3(7.5 \%)$ & $>0.05$ & Not significant \\
\hline
\end{tabular}

$*$ Calculated by $2 \times 2$ table (chi-square test).

Table 8: Distribution of patients according to mode of delivery.

\begin{tabular}{|lllll|}
\hline Mode of delivery & Group A $(\mathbf{n}=\mathbf{4 0})$ & Group B $(\mathbf{n}=\mathbf{4 0})$ & p-value & Significance \\
\hline Vaginal delivery & $37(92.5 \%)$ & $38(95 \%)$ & 0.502 & Not significant \\
\hline LSCS & $3(7.5 \%)$ & $2(5 \%)$ & & \\
\hline
\end{tabular}

Table 9: Neonatal outcome.

\begin{tabular}{|c|c|c|c|c|}
\hline Variable & Group A $(n=40)$ & Group B (n=40) & p-value & Significance \\
\hline Meconium aspiration & $2(5 \%)$ & $1(2.5 \%)$ & $>0.005$ & Not significant \\
\hline Admission to NICU & $2(5 \%)$ & $2(5 \%)$ & $>0.005$ & Not significant \\
\hline Observation & $3(7.5 \%)$ & $2(5 \%)$ & $>0.005$ & Not significant \\
\hline Stillbirth & 0 & 0 & $>0.005$ & Not significant \\
\hline \multicolumn{5}{|l|}{ Apgar score } \\
\hline $1 \min$ as $\leq 7$ & $8(20 \%)$ & $6(15 \%)$ & \multirow{2}{*}{$>0.005$} & \multirow{2}{*}{ Not significant } \\
\hline $5 \mathrm{~min}$ as $\leq 7$ & $6(15 \%)$ & $4(10 \%)$ & & \\
\hline
\end{tabular}

The induction delivery interval in Group A was18.12 \pm 3.68 and Group B was 18.22 \pm 4.1 (p-value 0.791 ) and was found to be comparable between the two groups. The need for further augmentation of labour was also compared between the two groups. In Group A spontaneous labour started in $20(50 \%)$ of the women compared to $17(42.5 \%)$ in Group B.

In Group A, 8 women required only oxytocin, 7 women required only ARM and 8 women required ARM+oxytocin for augmentation of labour. In Group B 15 women required only oxytocin infusion, 5 women required ARM only and 3 both ARM+oxytocin, however statistically there was no significant difference in need for augmentation of labour in both the groups, also no significant difference noted between the spontaneous vaginal delivery in both the groups, PGE2 group had 92.5\% vaginal deliveries whereas foley's group had 95\% successful vaginal deliveries. The need for caesarean section was also comparable in both the groups (Table 6, $7,8)$.

In Group A, 2 patients delivered after 24 hours and in Group B, 1 patient delivered after 24 hours. However, the mean duration of induction delivery interval was comparable between the two groups and the difference was not statistically significant (Table 6). 
The neonatal outcome was same in both the groups in all aspects and there was no statistically significant difference between the two groups. the incidence of perinatal asphyxia with Apgar score equal to $<7$ at 5 minutes was slightly higher in Group A as compared to Group B, although it was not statistically significant. NICU admission rate was similar i.e. $5 \%$ in both the groups and statistically insignificant (Table 9).

\section{DISCUSSION}

The results of the present study confirm that both PGE2 gel and foley's catheter are equally effective in preinduction ripening of cervix.

The change in bishop's score in PGE2 group was 3.25 which was highly significant ( $\mathrm{p}$ value $<0.001$ ), however comparison between the groups showed that one method did not confer statistically significant advantage over the other. The results of change in Bishop's score found in agreement with the study done by Dewan et al. ${ }^{3}$ The study conducted by Dahiya $\mathrm{K}$ et al, also showed that the change in bishop score after 6 hours was comparable to this study (in PGE2 group 4.6 \pm 1.48 and foley's group $4.18 \pm 1.81$ ), similar were the results of St Onge and Conners et al and Deshmukh et al. ${ }^{4-6}$

The mean duration of induction till onset of labour in PGE2 group was $11.0 \pm 4.3$ hours and foley's group was $10.94 \pm 3.1$ hours, which is comparable and showed statistically no significant difference between the two groups (p-value 0.718). Also, the induction delivery interval in PGE2 group was $18.21 \pm 11.13$ hours and in foley's group was $18.51 \pm 8.52$ and there was no significant difference statistically (0.791). Similar were the observations of the study done by Dahiya K et al, and Farah Ziyauddin et al. ${ }^{4,7}$

The mean duration from induction delivery interval in our study in PGE2 group was $18.12 \pm 3.68$ hours and foley's group was $18.22 \pm 4.1$ which is also comparable and showed statistically showed no significant difference between the two groups ( $p$ value 0.791). In the study conducted by Dahiya $\mathrm{K}$ et al at Rohtak the results of induction delivery interval found comparable to the present study (induction delivery interval in PGE2 group was $18.21 \pm 11.13$ and in foley's group was $18.51 \pm 8.52$ ), similar observations were noted by Deshmukh et al (in foley's group15.2 \pm 5.24 and PGE2 group14.2 \pm 4.6 hours). ${ }^{4,8}$ A study conducted by Jiyauddin $\mathrm{F}$ et al, in patients with previous caesarean section the mean induction delivery interval was 21.06 hours in PGE2 group and 18.15 hours in foley's group. ${ }^{7}$

The need for oxytocin induced augmentation of labour was $22.5 \%$ in PGE2 group and $37.5 \%$ in foley's group which was comparable with the study done by Dharamvijaya et al and Dewan et al.,
The rate of LSCS in PGE2 group was 5\% and in foley's group was $2.5 \%$ (p-value $>0.05$ ) and not statistically significant. There was no association of increased rate of caesarean section with foley's catheter or PGE2 gel, similar were the results of study done by Dharamvijaya et al, and Dewan et al. . $^{3,8}$

Fetal outcome data showed no significant difference between PGE2 gel group and foley's group, with respect to Apgar score, 1 min Apgar score $<7$ (20\% in PGE2 group and $15 \%$ in foley's group ) and Apgar score $<7$ at 5 min (15\% in PGE2 group and $10 \%$ in foley's group) which was not statistically significant. Thus, the present study shows that the fetal outcome results were also comparable in both the groups. Also, the total cost of foley's catheter was much less than PGE2 which was in agreement with studies done by Dewan et al, Dahiya K et al, Daramvijaya et al, Sciscione AC et al. . $^{3,4,8,9}$

\section{CONCLUSION}

Both PGE2 gel and foley's catheter showed equal efficacy for pre-induction ripening of cervix. Also, there was no difference in other outcomes like efficacy of labour induction, induction delivery interval, need for augmentation of labour and maternal and neonatal outcomes.

Moreover, foley's catheter found to be more cost effective as total cost of foley's catheter is less than PGE2 gel).

\section{Funding: No funding sources}

Conflict of interest: None declared

Ethical approval: The study was approved by the Institutional Ethics Committee

\section{REFERENCES}

1. WHO recommendation for induction of labour. Geneva: World Health Organization. 2011. Available at: https://www.ncbi.nlm.nih.gov/books/NBK131963 /. Accessed $11^{\text {th }}$ February 2020.

2. National institute for health excellence. Induction of labour. Landon; NICE 2008. Available at: https://www.nice.org.uk/guidance/cg70. Accessed on $11^{\text {th }}$ February 2020.

3. Dewan F, Ara AM, Begum A. Foley's catheter versus prostaglandin for induction of labour. Singap J Obstet Gynaecol. 2001;32:56-63.

4. Dahiya K, Malik K, Dahiya A, Nanda S. Comparison of the efficacy of Foley catheter balloon with dinoprostone gel for cervical ripening at term. Int $\mathbf{J}$ Clin Med. 2012;3(6):527-31.

5. St. Onge RD, Conners GT. Preinduction cervical ripening: a comparison of intracervical PGE2 gel vs. the Foley's catheter. AM J Obstet Gynaecol. 1995;172:687-90.

6. Deshmukh VL, Yelikar KA, Deshmukh AB. Comparative study of intra-cervical foley's catheter 
and PGE2 gel for pre-induction ripening (cervical). J Obstet Gynaecol India. 2011;61(4):418-21.

7. Ziyauddin F, Hakim S, Beriwal S. The transcervical foley catheter versus the vaginal prostaglandin e2 gel in the induction of labour in a previous one caesarean section - a clinical study. J Clin Diagn Res. 2013;7(1):140-3.

8. Dharmvijaya MN, Umashankar KM, Kavita G, Angure AG. Comparative study of intra-cervical Foleys catheter and PGE2 gel for pre-induction ripening. Int J Basic Appl Med Sci. 2013;3(1):24753.

9. Sciscione AC, McCullough H, Manley JS, Shlossman PA, Pollock M, Colmorgen GH. A prospective randomised comparison of foley catheter insertion vs intracervical PGE2 gel for pre-induction cervical ripening. Am J Obstet Gynecol. 1999;180:55-9.
10. National Institute for Clinical Excellence. Clinical guidelines for induction of labour, Appendix-E. London: NICE; 2001. Available at: https://www.nice.org.uk/guidance/cg70/evidence/cg7 0 -induction-of-labour-full-guideline. Accessed $11^{\text {th }}$ February 2020

11. Jozwiak M, Rengerink KO, Benthem M, Van Beek E, Dijksterhuis MG, De Graaf IM, et al. Foley catheter versus vaginal prostaglandin E2 gel for induction of labour at term (PROBAAT trial): an open-label, randomised controlled trial. Lancet. 2011;378(9809):2095-103.

Cite this article as: Anupma, Karya U, Gaikwad HS, Anamika, Shalini. A comparative study of transcervical foley's catheter with intracervical PGE2 gel for pre-induction cervical ripening. Int J Reprod Contracept Obstet Gynecol 2020;9:2581-6. 